\title{
The Differences of Characteristic, Management, Maternal and Perinatal Outcomes among Early and Late Onset Preeclampsia
}

\author{
Aryani Aziz, Johanes C. Mose \\ Department of Obstetrics and Gynecology, Faculty of Medicine, Padjadjaran University/Hasan Sadikin Hospital, \\ Bandung, Indonesia \\ Email: aryaniaziz88@gmail.com
}

Received 18 May 2016; accepted 26 June 2016; published 29 June 2016

Copyright (C) 2016 by authors and OALib.

This work is licensed under the Creative Commons Attribution International License (CC BY). http://creativecommons.org/licenses/by/4.0/

(c) (i) Open Access

\section{Abstract}

Objectives: Preeclampsia (PE) is still a problem in the field of obstetrics. This is due to the unclear etiology, morbidity and mortality are still high. Currently, there has been a change in the definition and understanding of Preeclampsiaa, Early Onset Preeclampsiaa (EOPE) and Late Onset Preeclampsiaa (LOPE). EOPE is a disorder accompanied by severe complications for both the mother and the perinatal due to placental factors, while LOPE is a disorder that is characterized by a mild complications in maternal from maternal disorders. This study aims to find differences in characteristics, management, maternal and perinatal outcomes to EOPE and LOPE. Methods: An analytic observational study was done with cross sectional design involving retrospective data 433 pregnant women with preeclampsia who delivered in Hasan Sadikin Hospital Bandung. Data were taken from January 2013 to December 2014. It was noted the characteristics, management, maternal and perinatal outcomes. Data were analyzed using parametric and nonparametric test with significance $p<0.05$. Results: The results showed that the incidence of EOPE $(27.5 \%)$ was lower than LOPE (72.5\%). Diastolic blood pressure is significantly higher in EOPE 109.71 \pm 10.761 and 106.05 \pm 8.871 compared to LOPE. The most spontaneous delivery is with EOPE labor $(91.2 \%)$ while in LOPE delivery with using forceps $(73.8 \%)$. Long of stay in EOPE at $5.59 \pm 6.90$ is longer than the LOPE at $5.32 \pm 4.70$. Complications in perinatal outcomes such as low birth weight $(<2500$ gram) are more in EOPE (97.5\%) compared to LOPE (45.6\%) and asphyxia is more on EOPE (11.7\%) compared to LOPE $(1.3 \%)$. Stillbirth in EOPE (16\%) is more than LOPE group (2.8\%). Conclusions: It is obtained that EOPE incidence rate is lower than LOPE. Mother and perinatal complications are greater in the EOPE group.

\section{Keywords}

Early Onset Preeclampsia and Late Onset Preeclampsia, Management, Maternal and Perinatal Outcomes 


\section{Introduction}

Preeclampsia (PE) is a condition in which the blood pressure is increase with or without proteinuria and may occur with or without the complications of other organs [1]-[4]. Preeclampsia is still a problem in the field of obstetrics. The incidence of PE ranges from 3\% - 5\% of births. This is due to the unclear etiology, and morbidity and mortality are still high [5]-[8].

Currently there has been a change in the definition and understanding of Preeclampsia, known as Early Onset Preeclampsia (EOPE) and Late Onset Preeclampsia (LOPE). This division is based on gestational age at patients with impaired blood pressure. EOPE is a PE that occurred at the gestational age of less than 34 weeks ( $<34$ weeks) and are usually accompanied by severe complications for both the mother and perinatal due to placental factors. While LOPE is a PE that occurred at the gestational age of 34 weeks ( $\geq 34$ weeks), and the disorder is accompanied by mild complications derived from maternal abnormalities [11]-[16].

Complications that occur in EOPE can cause severe problems either occur in both mother and fetus with increased morbidity and mortality. The latest research reported that termination of pregnancy labor $<34$ weeks would be better in termination of better maternal dan perinatal outcomes [11] [12] [17].

This study aimed at determining the differences in characteristics, management, maternal and perinatal outcomes of EOPE and LOPE hospitalized in Hasan Sadikin Hospital Bandung during 2 years periode in 20132014.

\section{Methods}

Retrospective data of PE mother were obtained from medical records of Hasan Sadikin Hospital in Bandung for two years from 2013-2014. Data were analyzed based on inclusion and exclusion criteria in the form of a single pregnancy, which noted characteristics such as age, education, parity and systolic and diastolic blood pressure. Data that support for maternal outcomes include duration of treatment, mode of delivery, type of anesthesia. Data transform and outputs include birth weight baby and apgar score in the 5th minute [17]-[19].

Preeclampsia defined by The International Society for the Study of Hypertension in Pregnancy (ISSP) is an increase in systolic blood pressure $\geq 160 \mathrm{mmHg}$ or diastolic $\geq 110 \mathrm{mmHg}$ pregnancy after a gestation $>20$ weeks with or without maternal complications. PE differentiated by gestational age $<34$ weeks (EOPE) and gestational age $\geq 34$ weeks (LOPE) [9] [10].

\section{Statistic Analysis}

Data were analyzed using parametric statistical tests and non-parametric. riteria significance is with $p<0.05$.

\section{Result}

Based on data from medical records of Hasan Sadikin hospital in 2013-2014, it was obtained data with PE 489 patients. A total of 56 patients were excluded so that the data can be analyzed as many as 433 patients. From these data, a total of EOPE are 119 patients (27.5\%) and 314 patients are LOPE (72.5\%) (Figure 1).

\section{Data Characteristic}

This study was conducted to pregnant women with Preeclampsia as many as 433 person. A total of 279 (64.4\%) deliveries occurred in the age range of 20 - 35 years. Education of PE patients is high school as 164 (37.9\%). Based on the gestational age of PE, LOPE patients ( $\geq 34$ minggu) were 314 ( $72.5 \%$ ) more than EOPE ( $<34$ minggu) 119 (27.5\%). Patients with PE occurred at multigravida were 255 (58.9\%). While the systolic blood pressure was on average $170.33 \pm 14.43$ and mean diastolic $107.06 \pm 9.557$. Long of stay was over 3 days of 274 (63.3\%) (Table 1).

Table 2 shows that the characteristics of the age and education are not significant in EOPE and LOPE group ( $p$ $<0.05)$. Multigravida was found more in EOPE, while primigravida was more in LOPE $(p<0.05)$. Not associated 


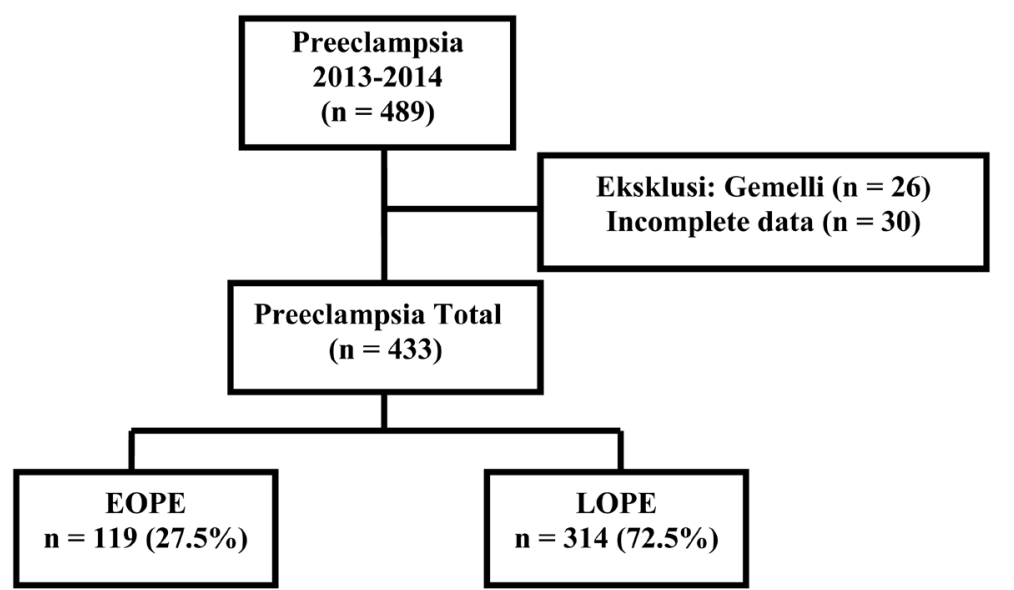

Figure 1. Patients with PE Hasan Sadikin Hospital in 2013-2014.

Table 1. Characteristic of patients with PE.

\begin{tabular}{|c|c|c|}
\hline Variable & $2013(n=217)$ & $2014(n=216)$ \\
\hline \multicolumn{3}{|l|}{ Age (years) } \\
\hline$<20$ & 17 (7.8\%) & $33(15.3 \%)$ \\
\hline $20-35$ & $148(68.2 \%)$ & $131(60.6 \%)$ \\
\hline$>35$ & $52(24.0 \%)$ & $52(24.1 \%)$ \\
\hline \multicolumn{3}{|l|}{ Education } \\
\hline Elementary & $57(26.3 \%)$ & 47 (21.8\%) \\
\hline Middle School & $60(27.6 \%)$ & $71(32.9 \%)$ \\
\hline High School & $74(34.1 \%)$ & $90(41.7 \%)$ \\
\hline College & $26(12.0 \%)$ & $8(3.7 \%)$ \\
\hline \multicolumn{3}{|c|}{ Gestational age (weeks) } \\
\hline$<34$ & $60(27.6 \%)$ & $59(27.3 \%)$ \\
\hline$\geq 34$ & $157(72.4 \%)$ & $157(72.7 \%)$ \\
\hline \multicolumn{3}{|l|}{ Parity } \\
\hline Primigravida & $89(41.0 \%)$ & $89(41.2 \%)$ \\
\hline Multigravida & $128(59.0 \%)$ & 127 (58.8\%) \\
\hline \multicolumn{3}{|c|}{ Blood Pressure (mmHg) } \\
\hline \multicolumn{3}{|l|}{ Systolic } \\
\hline Mean \pm Std & $170.36 \pm 14.93$ & $170.30 \pm 13.95$ \\
\hline Median & 170.00 & 170.00 \\
\hline Range (min-max) & $120.00-230.00$ & $140.00-250.00$ \\
\hline \multicolumn{3}{|l|}{ Diastolic } \\
\hline Mean \pm Std & $107.08 \pm 9.804$ & $107.03 \pm 9.325$ \\
\hline Median & 110.00 & 110.00 \\
\hline Range (min-max) & $90.00-160.00$ & $60.00-150.00$ \\
\hline
\end{tabular}

Note: For numeric data are presented with mean, standard deviation, median, and range (min-max). For categorical data are presented in proportions. 
Table 2. Characteristic of patients EOPE and LOPE.

\begin{tabular}{|c|c|c|c|}
\hline Variable & $\operatorname{EOPE}(n=119)$ & LOPE $(n=314)$ & $p$ \\
\hline Age (years) & & & 0.473 \\
\hline Mean \pm Std & $173.16 \pm 17.90$ & $169.26 \pm 12.75$ & \\
\hline Median & 170.00 & 170.00 & \\
\hline Range (min-max) & $140.00-250.00$ & $120.00-230.00$ & \\
\hline Education & & & 1.000 \\
\hline Elementary & 29 (24.4\%) & 75 (23.9\%) & \\
\hline Middle School & 36 (30.3\%) & 95 (30.3\%) & \\
\hline High School & $44(37.0 \%)$ & $120(38.2 \%)$ & \\
\hline College & $10(8.4 \%)$ & $24(7.6 \%)$ & \\
\hline Parity & & & $\mathbf{0 . 0 1 7}^{* *}$ \\
\hline Primigravida & $64(53.8 \%)$ & $184(58.6 \%)$ & \\
\hline Multigravida & 55 (46.2\%) & $130(41.4 \%)$ & \\
\hline Blood pressure (mmHg) & & & 0.073 \\
\hline \multicolumn{4}{|l|}{ Systolic } \\
\hline Mean \pm Std & $173.16 \pm 17.90$ & $169.26 \pm 12.75$ & \\
\hline Median & 170.00 & 170.00 & \\
\hline Range (min-max) & $140.00-250.00$ & $120.00-230.00$ & \\
\hline Diastolic & & & $0.002^{* *}$ \\
\hline Mean \pm Std & $109.71 \pm 10.761$ & $106.05 \pm 8.871$ & \\
\hline Median & 110.00 & 110.00 & \\
\hline Range (min-max) & $100.00-150.00$ & $60.00-160.00$ & \\
\hline
\end{tabular}

Note: For numeric data $p$ value was calculated based on the unpaired t test when the normal distribution of data as well as alternative Mann Whitney test if the data are not normally distributed. For categorical data and the p-value is calculated based on Chi-Square test. With the Fisher Exact alternative test if the requirements of the Chi-Square is not obtained. Significance score was based on the value of $p<0.05$. Sign ${ }^{*}$ indicates $p<0.05$ means significance or statistically significant.

with an increase in systolic blood pressure were significant in both groups, but to an increase in diastolic blood pressure more on EOPE than LOPE $(p<0.05)$. EOPE was a longer treated group compared to LOPE $(p<0.05)$.

Table 3 illustrates the comparison of outcomes in patients EOPE and LOPE. Most deliveries performed by cesarean section, are respectively by 58\% (EOPE) and 50.6\% (LOPE). There is lots of spontaneous labor to EOPE group compared to LOPE $(p<0.05)$. Deliveries using forceps are more in LOPE groups than in EOPE $(p<0.05)$. General anesthesia is more in EOPE group (41.2\%), while block anesthesia is more in LOPE group (20.4\%).

In the assessment of outcomes (Table 4) showed that in the group of EOPE is more babies born weighing $<2500 \mathrm{~g}(97.5 \%)$ where as in the group LOPE is more weight infants $\geq 2500$ grams (54.5\%). Babies who are born in EOPE groups suffer asphyxia (11.7\%) more than babies in LOPE group (1.3\%). Stillbirth in EOPE group (16\%) are more than in LOPE group (2.8\%).

\section{Discussion}

Data were taken from the data of PE patients in Hasan Sadikin Hospital for 2 years in 2013 and 2014. This study was conducted to determine how much influence the occurrence of PE based on the characteristics of maternal gestational age, management, maternal and infant outcomes. 
Table 3. Maternal outcomes of EOPE and LOPE.

\begin{tabular}{|c|c|c|c|}
\hline Variable & EOPE $(n=119)$ & LOPE $(n=314)$ & $p$ \\
\hline Mode of Delivery & & & 0.366 \\
\hline SC & $64(53.8 \%)$ & $184(58.6 \%)$ & \\
\hline Vaginal & $55(46.2 \%)$ & $130(41.4 \%)$ & \\
\hline Vaginal Delivery & & & $0.0001^{* *}$ \\
\hline Spontaneous & $52(91.2 \%)$ & $31(23.8 \%)$ & \\
\hline Forceps & $3(5.3 \%)$ & $96(73.8 \%)$ & \\
\hline Vacuum & $0(0.0 \%)$ & $2(1.6 \%)$ & \\
\hline Embriotomi & 2 (3.5\%) & $1(0.8 \%)$ & \\
\hline Anesthesia & & & 0.680 \\
\hline General & 49 (41.2\%) & $105(33.4 \%)$ & \\
\hline Block Anesthesia & $11(9.2 \%)$ & $64(20.4 \%)$ & \\
\hline No Anesthesia (Vaginal) & 59 (49.6\%) & $145(46.2 \%)$ & \\
\hline Long of Stay (days) & & & $0.0001^{* *}$ \\
\hline Mean \pm Std & $5.59 \pm 6.90$ & $5.32 \pm 4.70$ & \\
\hline Median & 4.00 & 4.00 & \\
\hline Range (min-max) & $1.00-92.00$ & $1.00-35.00$ & \\
\hline
\end{tabular}

Note: For numeric data $p$ value was calculated based on the unpaired t test when the normal distribution of data as well as alternative Mann Whitney test if the data are not normally distributed. For categorical data and the $p$-value is calculated based on Chi-Square test. With the Fisher Exact alternative test if the requirements of the Chi-Square is not obtained. Significance score was based on the value of $p<0.05$. Sign ${ }^{*}$ indicates $p<0.05$ means significance or statistically significant.

Table 4. Perinatal outcomes of EOPE and LOPE.

\begin{tabular}{|c|c|c|c|}
\hline Variable & $\operatorname{EOPE}(n=119)$ & LOPE $(n=314)$ & $p$ \\
\hline Birth Weight (grams) & & & $0.0001^{* *}$ \\
\hline$<000$ & 107 (89.9\%) & 47 (15.0\%) & \\
\hline $2000-2499$ & $9(7.6 \%)$ & $96(30.6 \%)$ & \\
\hline$\geq 2500$ & $3(2.5 \%)$ & 171 (54.5\%) & \\
\hline Apgar Score (minute 5) & & & $0.0001^{* *}$ \\
\hline Asphyxia $(\leq 3)$ & $14(11.7 \%)$ & $4(1.3 \%)$ & \\
\hline Not Asphyxia (>3) & $86(72.3 \%)$ & 301 (95.9\%) & \\
\hline Stillbirth & $19(16.0 \%)$ & $9(2.8 \%)$ & \\
\hline
\end{tabular}

Note: For categorical data the p-value is calculated based on Chi-square test with Fisher Exact alternative test and Kolmogorov Smirnov if the requirements of the Chi-Square is not obtained. Significance score is based on the value of $p<0.05$. Sign ${ }^{*}$ indicates $p<0.05$ means significance or statistically significant.

The study group was divided into 2 occurred PE based on gestational age. EOPE is PE with a gestational age less than 34 weeks ( $<34$ minggu) while LOPE is PE with gestational age greater than or equal to 34 weeks $(\geq 34)$. Complications in EOPE are heavier than LOPE due to placental factors and occurs in pregnancy <34 minggu [18]. EOPE complications occur in women including increased blood pressure both systolic and diastolic thus require longer treatment than LOPE. Babies born from EOPE mother get more in trouble. Babies who are born in EOPE 
groups suffer asphyxia and low birth weight more than babies in LOPE group [19]-[21]. In this study, increased blood pressure only in diastolic that significant.

In this study, the EOPE is only by $27.5 \%$ lower compared with LOPE is $72.5 \%$ [17]. Data from Pettit study incidence EOPE is $13 \%$ [22].

The mode of delivery either on EOPE or LOPE is done caesarean section. Different from Pettit etal study, caesarean section is more in EOPE group (70\%) compares LOPE group (40\%) [22]. However the vaginal delivery in EOPE is lot to do with the spontaneous process by induction of labor. This is possible because of babies born weighing less than normal. In LOPE, vaginal delivery is done by using the aid of either with forceps [17].

Perinatal outcomes in EOPE patients are more likely to endurance lower due to be born with lower birth weight and the possibility of breathing difficulties (asphyxia) is greater than the LOPE patients [22]-[24].

Infants of mothers with EOPE, in particular those born at $<34$ weeks, had increased perinatal morbidity and mortality compared to infants from $\geq 34$ weeks [21].

A recent review by Sibai supported expectant management in selected cases of severe PE presenting before 34 weeks [20] [21] [25]. Good perinatal outcomes were reported in centre equipped to management hight-risk pregnancies and premature neonatus. The provision of MgSO4 40\% as a brain protector and corticosteroids to infant lung maturation can reduce complications of peronatal outcomes. Hall reported no increased in maternal complications when women who presented before $<34$ weeks were managed expectantly. The caesarean section rates were high at $82 \%$ and women were delivered once they reached 34 weeks gestation [12] [25].

\section{Conclusions}

1) The incidence of EOPE is lower (27.5\%) than LOPE (72.5\%).

2) EOPE group experienced more complications for both the fetus and the mother.

3) Diastolic blood pressure is higher in EOPE than LOPE.

4) Spontaneous delivery more in EOPE, while LOPE ends with action by using forceps.

5) EOPE long of stay in hospital is longer than LOPE.

6) Low birth weight ( $<2500$ gram) with asphyxia is more on EOPE.

7) Stillbirth EOPE is more than LOPE group.

\section{Suggestions}

Because EOPE has the maternal characteristics with the mother and infant outcomes that are worse than LOPE so the management requires special attention by doing something more active, including the provision of $\mathrm{MgSO}_{4} 40 \%$ as a brain protector and corticosteroids to infant lung maturation prior to termination of pregnancy.

\section{References}

[1] Lisonkova Joseph, K.S. (2013) Incidence of Preeclampsia: Risk Factors and Outcomes Associated with Early- versus Late-Onset Disease. American Journal of Obstetrics \& Gynecology, 209, 544.e1-544 e12.

[2] Hutcheon, J.A., Lisonkova, S. and Joseph, K.S. (2011) The Epidemiology of Preeclampsia and the Hyper-Tensive Disorders of Pregnancy. Best Practice \& Research Clinical Obstetrics \& Gynaecology, 25, 391-403. http://dx.doi.org/10.1016/j.bpobgyn.2011.01.006

[3] Sibai, B., Dekker, G. and Kupferminc, M. (2005) Pre-Eclampsia. Lancet, 365, 785-799. http://dx.doi.org/10.1016/S0140-6736(05)71003-5

[4] Khan, K.S., Wojdyla, D., Say, L., Gulmezoglu, A.M. and Van Look, P.F. (2006) WHO Analysis of Causes of Maternal Death: A Systematic Review. Lancet, 367, 1066-1074. http://dx.doi.org/10.1016/S0140-6736(06)68397-9

[5] Steegers, E.A.P., Von Dadelszen, P., Duvekol, J.J. and Pijnenborg, R. (2010) Preeclampsia. Lancet, 376, 631-644. http://dx.doi.org/10.1016/S0140-6736(10)60279-6

[6] Kuklina, E.V., Ayala, C. and Callaghan, W.M. (2009) Hyper-Tensive Disorders and Severe Obstetric Morbidity in the United States. Obstetrics \& Gynecology, 113, 1299-1306. http://dx.doi.org/10.1097/AOG.0b013e3181a45b25

[7] Knight, M. (2007) Eclampsia in the United Kingdom, 2005. BJOG, 114, 1072-1078. http://dx.doi.org/10.1111/j.1471-0528.2007.01423.x

[8] MacKay, A.P., Berg, C.J. and Atrash, H.K. (2001) Pregnancy-Related Mortality from Pre-Eclampsia and Eclampsia. Obstetrics \& Gynecology, 97, 533-538.

[9] Tranquilli, A.L., Brown, M.A., Zeeman, G.G., Dekker, G., Sibai, B.M., The Definition of Severe and Early-Onset Pre- 
eclampsia (2013) Statements from the International Society for the Study of Hypertension in Pregnancy (ISSHP). Pregnancy Hypertension, 3, 44-47. http://dx.doi.org/10.1016/j.preghy.2012.11.001

[10] Tranquilli, A.L., Dekker, G., Magee, L., et al. (2014) The Classification, Diagnosis and Management of the Hypertensive Disorders of Pregnancy: A Revised Statement from the ISSHP. Pregnancy Hypertension, 4, 97-104. http://dx.doi.org/10.1016/j.preghy.2014.02.001

[11] Publications Committee Sfm-FM, Sibai, B.M. (2011) Evaluation and Management of Severe Preeclampsia before 34 Weeks’ Gestation. American Journal of Obstetrics \& Gynecology, 205, 191-198. http://dx.doi.org/10.1016/j.ajog.2011.07.017

[12] Hall, D.R., Odendaal, H.J., Steyn, D.W. and Grove, D. (2000) Expectant Management of Early Onset, Severe Preeclampsia: Maternal Outcome. BJOG, 107, 1252-1257. http://dx.doi.org/10.1111/j.1471-0528.2000.tb11616.x

[13] Raymond, D. and Peterson, E. (2011) A Critical Review of Early-Onset and Late-Onset Preeclampsia. Obstetrical \& Gynecological Survey, 66, 497-506.

[14] Roberts, J.M. and Hubel, C.A. (2009) The Two Stage Model of Pre-Eclampsia: Variations on the Theme. Placenta, 30, S32-S37. http://dx.doi.org/10.1016/j.placenta.2008.11.009

[15] Ness, R.B. and Roberts, J.M. (1996) Heterogeneous Causes Constituting the Single Sydrome of Pre-Eclampsia: A Hypothesis and Its Implication. American Journal of Obstetrics \& Gynecology, 175, 1365-1370. http://dx.doi.org/10.1016/S0002-9378(96)70056-X

[16] Von Dadelszen, P., Magee, L.A. and Roberts, J.M. (2003) Subclassification of Pre-Eclampsia. Hypertension in Pregnancy, 22, 143-148. http://dx.doi.org/10.1081/PRG-120021060

[17] Evidence CfEa (2012) New South Wales Maternal and Babies Report 2010, [10347674].

[18] Lowe, S.A., Brown, M.A., Dekker, G.A., et al. (2009) Guidelines for the Management of Hypertensive Disorders of Pregnancy 2008. Australian and New Zealand Journal of Obstetrics and Gynaecology, 49, 242-246. http://dx.doi.org/10.1111/j.1479-828X.2009.01003.x

[19] Churchill, D., Duley, I., Thornton, J.G. and Jones, I. (2013) Interventionist versus Expectant Care for Severe PreEclampsia between 24 and 34 Weeks' Gestation. Cochrane Database of Systematic Reviews, No. 7, Article ID: CD0033106. http://dx.doi.org/10.1002/14651858.cd003106.pub2

[20] Sibai, B.M. (2011) Management of Late Pretern and Early-Term Pregnancies Complicated by Mild Gestational Hypertension/Pre-Eclampsia. Seminars in Perinatology, 35, 292-296. http://dx.doi.org/10.1053/j.semperi.2011.05.010

[21] Resnick, M.B., Armstrong, S. and Carter, R.I. (1988) Developemental Intervention Program for High-Risk Premature Infants Interactions. Journal of Developmental \& Behavioral Pediatrics, 9, $73-78$.

Steegers, E.A.P., Von Dadelszen, P., Duvekot, J.J. and Pijnenborg, R. (2010) Pre-Eclampsia. The Lancet, 376, 631-644. http://dx.doi.org/10.1016/S0140-6736(10)60279-6

[22] Pettit, F., Mangos, G., Davis, G., Henry, A. and Brown, M.A. (2015) Preeclampsia Causes Adverse Maternal Outcomes across the Gestational Spectrum. Pregnancy Hypertension: An International Journal of Women's Cardiovascular Health, 5, 198-204.

[23] Paruk, F. and Moodley, J. (2000) Maternal and Neonatal Outcome in Early- and Late-Onset Pre-Eclampsia. Seminars in Neonatology, 5, 197-207. http://dx.doi.org/10.1053/siny.2000.0023

[24] Hall, D.R., Odendaal, H.J., Kirsten, G.F., Smith, J. and Grove, D. (2000) Expectant Management of Early Onset, Severe Pre-Eclampsia: Perinatal Outcome. BJOG: An International Journal of Obstetrics \& Gynaecology, 107, 12581264. http://dx.doi.org/10.1111/j.1471-0528.2000.tb11617.x

[25] Sibai, B.M. (2013) What to Expectant Management in Severe Preeclampsia at <34 Weeks Gestation: Pregnancy Outcomes in Developed vs Developing Countries. American Journal of Obstetrics and Gynecology, 209, 400-401. http://dx.doi.org/10.1016/j.ajog.2013.08.024 


\section{Warmly welcome your paper submission to OALib Journal!}

- Publication on a daily basis

- 9 subject areas of science, technology and medicine

- Fair and rigorous peer-review system

- Fast publication process

- Article promotion in various social networking sites (LinkedIn, Facebook, Twitter, etc.)

- Widely-targeted and multidisciplinary audience to read your research

Submit Your Paper Online: Click Here to Submit

Contact Us: service@oalib.com 